\title{
Nimodipine prevents medial septal lesion-induced performance deficits in the Morris water maze
}

\author{
ANTHONY W. BANNON, KATHLEEN MCMONAGLE-STRUCKO, \\ and RICHARD J. FANELLI \\ Institute for Dementia Research, Miles Inc., West Haven, Connecticut
}

\begin{abstract}
The effects of nimodipine were investigated on performance of rats with medial septal nucleus lesions in the Morris water maze. The paradigm began with 10 training trials followed by an initial probe trial. The rats were then assigned to treatment groups: sham-vehicle, shamnimodipine, lesion-vehicle, and lesion-nimodipine. The doses of nimodipine used were 3,10 , and $30 \mathrm{mg} / \mathrm{kg}$, p.o. Sham or lesion surgeries were performed and drug or vehicle treatments started after surgery, and continued for the duration of the study. Seven days postsurgery, the rats were given a second probe trial, followed by 4 additional training trials. A third probe trial was then conducted. Prior to surgery, all the rats performed equally during initial training. On the first probe trial, the amount of time spent in the goal quadrant was greater than chance for all animals. After surgery, during the second probe trial, no significant drug and/or lesion effects were found. During the third probe trial, however, the performance of the lesion-vehicle animals was not greater than chance. In nimodipine-treated rats, as in sham controls, this deficit was not found. These results indicate that nimodipine can protect against medial septal lesion-induced retention deficits.
\end{abstract}

Cholinergic innervation of the hippocampus must be intact for appropriate performance of various memory tasks. In rodents, cholinergic afferents to the hippocampus originate primarily from cell bodies in the medial septal area (MS) and reach the hippocampus through the fimbria fornix (FF) (Lewis \& Shute, 1967; Mesulam, Mufson, Wainer, \& Levey, 1983). Lesions of the MS or FF lead to disruption of performance by rats in the eight-arm radial maze (RAM), the Morris water maze, and the Tmaze (Cassel et al., 1992; Hagan, Salamone, Simpson, Iversen, \& Morris, 1988; Hepler, Olton, Wenk, \& Coyle, 1985). In these models, augmentation of the cholinergic system can be effective in ameliorating memory deficits normally induced by these lesions. For example, in rats with MS lesions, Matsuoka, Maeda, Ohkubo, and Yamaguchi (1991) found beneficial effects on spatial memory with the cholinesterase inhibitor physostigmine, and with pilocarpine, a muscarinic agonist. In addition to classic cholinergic manipulations such as cholinesterase inhibition, other treatments have been found to be successful in alleviating the amnestic effects induced by deafferentation of the cholinergic input to the hippocampus.

Kinoshita, Kameyama, Hasegawa, and Nabeshima (1992) showed that vinconate, a vinca alkaloid, improved RAM performance of rats with MS lesions. Although vinconate has been shown to inhibit $\left[{ }^{3} \mathrm{H}\right]$ quinuclidinyl benzilate binding at muscarinic receptors, the compound may

Address correspondence to R. J. Fanelli, Institute for Dementia Research, Miles Inc., 400 Morgan Lane, West Haven, CT 06516-4175. have other actions (i.e., neuroprotection). Also, in aged rats, nerve growth factor (NGF) can improve retention of a spatial memory task (Fischer et al., 1987). In aged rats, degenerative changes in forebrain cholinergic nuclei have been correlated with cognitive deficits (Fischer, Gage, \& Björklund, 1989). More recently, Pallage, Orenstein, and Will (1992) demonstrated that a single intracerebral injection of NGF given at the time of MS lesion surgery reduced the number of errors in a RAM task by rats. The mechanism of action for this effect is not completely understood. Another compound that has been shown to have beneficial effects on cognition in animal models of central nervous system (CNS) dysfunction is nimodipine, a dihydropyridine calcium channel blocker (Scriabine, Schuurman, \& Traber, 1989).

The purpose of the present study was to determine if nimodipine could alleviate memory deficits induced by MS lesions in rats. Aged rabbits administered intravenous nimodipine have shown accelerated acquisition learning of an eyeblink conditioning task (Deyo, Straube, \& Disterhoft, 1989). In rats with lesioned visual neocortex, oral nimodipine was found to expedite the recovery of performance in a brightness discrimination task (LeVere, Brugler, Sandin, \& Gray-Silva, 1989). Also, McMonagleStrucko and Fanelli (1993) have shown that rats of several ages that were treated with chronic nimodipine showed enhanced performance on probe (e.g., retention) trials during a reversal procedure of the Morris water maze. In the present research, the effects of three doses of nimodipine (p.o.) on performance of a water maze task were studied in young adult rats with MS lesions. 


\section{METHOD}

\section{Subjects}

Male Long-Evans rats were obtained from Charles River Laboratories and individually housed with ad-lib access to food and water for the duration of the study. The animal facility was maintained on a 12:12-h light:dark cycle with lights on at 7 a.m. Temperature in the facility was maintained at $22^{\circ} \pm 2^{\circ} \mathrm{C}$, with a humidity level of $55 \% \pm 10 \%$. All behavioral testing was conducted between 800 and $1600 \mathrm{~h}$.

\section{Water Maze}

The behavioral apparatus utilized in this study has been described in detail by McMonagle-Strucko and Fanelli (1993). Briefly, a circular galvanized steel tank with a diameter of $1.47 \mathrm{~m}$ was divided into equivalent quadrants. In each of the quadrants, there was a plastic fitting that allowed for the placement of an escape platform. Prior to the start of behavioral testing, the maze was filled with water to a depth $1 \mathrm{~cm}$ above the escape platform. The water temperature was maintained at approximately $26^{\circ} \mathrm{C}$, and was made opaque by the addition of $0.9 \mathrm{~kg}$ of powdered milk. Numerous stationary visual cues were present in the testing room. The data were recorded with the Multiple Zone Distance Traveled program of the Videomex-V analysis system (Columbus Instruments International Corp., Columbus, $\mathrm{OH}$ ).

\section{Surgery}

The rats were anesthetized with sodium pentobarbital $(65 \mathrm{mg} / \mathrm{kg}$; i.p.) and placed in a stereotaxic instrument. A rostral-caudal incision was made to the scalp in order to expose the skull. Coordinates, determined from the atlas of Paxinos and Watson (1986), were at midline and $0.7 \mathrm{~mm}$ anterior of bregma. Once a hole had been drilled in the skull for electrode (Radionics TC 4112; David Kopf Instruments, Tujunga, CA) placement, the electrode was lowered to a depth of $5.0 \mathrm{~mm}$ ventral from dura. For sham animals, the electrode was left in place for $60 \mathrm{sec}$ without current. For lesioned animals, the lesion generator (Radionics RFG-4A; David Kopf Instruments) was turned on for $60 \mathrm{sec}$. Timing began when the electrode temperature reached $70^{\circ} \mathrm{C}(\mathrm{V} \approx 18 ; \mathrm{mA} \approx 4)$. Following completion of sham or lesion surgery, the scalp was closed with wound clips and the rats were allowed 7 days to recover.

\section{Histology}

Frozen sections $(20 \mu \mathrm{m})$ were taken through the area of the lesion and slide mounted for staining with cresyl violet. The stained sections were used for verification of lesion placement and size. Based on the atlas of Paxinos and Watson (1986), the septal area was defined. Animals with lesions not located in the septal area, or lesions that included areas outside of the medial septal area (i.e., lateral septum) were excluded from statistical analysis.

\section{Protocol}

After 1 week of acclimation to the animal facility, the rats were given a 30 -sec free swim, during which no escape platform was present. Next, acquisition training began. The rats were pseudorandomly assigned (i.e., equal number assigned to each of the quadrants) a goal quadrant in which the escape platform was located. A total of 10 acquisition trials were given, 2 each day for 5 days. No drug treatments were given during this initial acquisition training. The rats were placed into the maze from one of four equally spaced positions around the perimeter of the tank. The starting position varied for each rat until they had started from each of the four positions at least once. The rats were allowed $120 \mathrm{sec}$ to find the goal platform; if the platform was not found prior to $120 \mathrm{sec}$, the animal was placed on the platform by the experimenter for $25 \mathrm{sec}$. The second trial of each day began approximately $25 \mathrm{sec}$ after completion of the first trial. On Day 5 of training, immediately after the second acquisition trial, the rats were given a $30-\mathrm{sec}$ probe trial-Probe 1. During the probe trial, no escape platform was present and the time spent in each quadrant was measured.

Two days after completion of Probe 1 , the rats were randomly assigned to one of six groups: (1) sham-vehicle $(n=10)$; (2) sham$10 \mathrm{mg} / \mathrm{kg}$ nimodipine $(n=10)$; (3) lesion-vehicle $(n=8)$; (4) lesion$3 \mathrm{mg} / \mathrm{kg}$ nimodipine $(n=9) ;(5)$ lesion- $10 \mathrm{mg} / \mathrm{kg}$ nimodipine $(n=$ 8 ); or lesion- $30 \mathrm{mg} / \mathrm{kg}$ nimodipine $(n=7)$. The rats in the lesion groups received an electrolytic lesion of the medial septal area; those in the sham groups received the same surgery with no current passing through the electrode. After surgery, the rats were given a 7-day recovery period. The rats received a single dose of either vehicle or nimodipine after surgery. For the next 4 days of recovery, they were given their respective treatments twice per day $(9: 00 \mathrm{a} . \mathrm{m}$. and 4:00 p.m.). Nimodipine was suspended in $1 \%$ methylcellulose; the rats not treated with nimodipine received a $1-\mathrm{ml} / \mathrm{kg}$ dose of the vehicle.

After the 7-day recovery period, behavioral testing in the water maze resumed. The rats were given a single probe trial-Probe $2-$ followed by four additional training trials (120-sec cutoff). The additional training trials were started $24 \mathrm{~h}$ after Probe 2 . During the additional trials, the goal quadrant remained the same as that utilized during initial training, but only one trial per day was conducted. Twenty-four hours after completion of the additional training trials, the rats were given another probe trial-Probe 3. On the days of behavioral testing conducted after surgery, they were treated with a single dose of drug or vehicle $1 \mathrm{~h}$ prior to behavioral testing.

One day after the conclusion of behavioral testing, the rats were decapitated and blood samples were collected; they had been dosed with either nimodipine or vehicle approximately $1 \mathrm{~h}$ before the samples were taken. The blood samples were stored at $-80^{\circ} \mathrm{C}$ until analyzed for the presence of nimodipine, using the method of Krol et al. (1987). The brains were removed and frozen in preparation for histological examination.

\section{Statistics}

Plasma levels of nimodipine were analyzed by analysis of variance (ANOVA), followed by Fisher's $L S D$ test. The water maze data from the training and additional trials were analyzed by ANOVA with group and day as factors. For probe trial data, the percentage of time spent in the goal quadrant for each group was compared with chance performance, $25 \%$, with the Mann-Whitney $U$ statistic. Within-group comparisons between Probe 1 and Probes 2 and 3 were made with Wilcoxon's matched-pairs test. The level of significance for all analyses was set at $p<.05$.

\section{RESULTS}

\section{Plasma Nimodipine}

Plasma nimodipine levels are shown in Table 1. Drug treatments were started after lesion or sham surgery and continued for the duration of the study. A significant group effect was found $[F(5,53)=2.97, p<.019]$. Further analysis indicated that the lesion $-30-\mathrm{mg} / \mathrm{kg}$ nimodipine

Table 1

\begin{tabular}{cc} 
Plasma Nimodipine Levels $(\boldsymbol{M} \pm \mathbf{S E M})$ & in Treated Groups \\
\hline Group & Nimodipine $(\mathrm{ng} / \mathrm{ml})$ \\
\hline Sham-10 $\mathrm{mg} / \mathrm{kg}$ nimodipine & $8.4 \pm 2.04$ \\
Lesion-3 $\mathrm{mg} / \mathrm{kg}$ nimodipine & $5.8 \pm 1.85$ \\
Lesion-10 $\mathrm{mg} / \mathrm{kg}$ nimodipine & $8.9 \pm 2.57$ \\
Lesion-30 mg/kg nimodipine & $15.4 \pm 5.53$ \\
\hline
\end{tabular}


group had a significantly higher nimodipine level than the sham-vehicle, lesion-vehicle, and lesion-3-mg/kg nimodipine groups (all $p s<.05$ ).

\section{Lesion Description}

Figure 1 is a diagram of a typical septal lesion in this experiment with respect to size and placement. In general, the lesions produced were small and did not result in complete destruction of the medial septal area.

\section{Water Maze}

Initial training. The time required to find the escape platform (escape latency) decreased over the course of acquisition training $[F(4,280)=66.748, p<.001]$. All the groups exhibited similar levels of performance by the end of the training period (data not shown).

Probe 1. During Probe 1, all the groups spent a significantly higher percentage of time in their respective goal quadrants compared with the chance level of $25 \%$, suggesting that all the rats had learned the location of the escape platform (see Figure 2).

Probe 2. Probe 2 was conducted after surgery and recovery, during which time drug treatments began. The data showing the percentage of time spent in the goal quadrant during Probe 2 are shown in Figure 3. The rats in the sham-10-mg/kg nimodipine and lesion $-3-\mathrm{mg} / \mathrm{kg}$ nimodipine groups did not perform at levels that were significantly above chance. For each of the other groups, the level of performance was better than chance (all $p s<$ .05 ) during Probe 2. No significant lesion or drug effect was apparent at this point.

Additional training. An overall significant effect of day was found for escape latency during the four additional training trials that followed Probe $2[F(3,182)=$ $3.174, p<.025]$. The decreases in escape latencies over the course of these training trials indicated that the performance of the rats was improving. Significant group differences were not found for escape latency during this period (data not shown).

Probe 3. The data from Probe 3 are shown in Figure 4. Probe 3 was carried out $24 \mathrm{~h}$ after completion of four additional training trials to the same goal quadrant that was

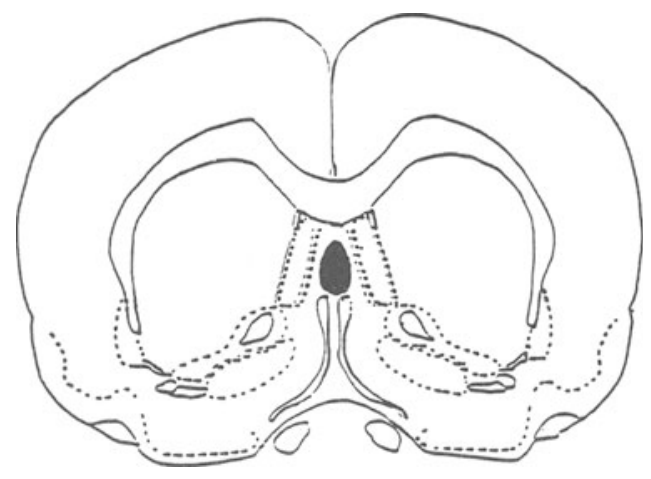

Figure 1. Diagram representing typical septal lesion. Dark area represents area of lesion. This figure is modified from plate 18 of Pellegrino, Pellegrino, and Cushman (1979).

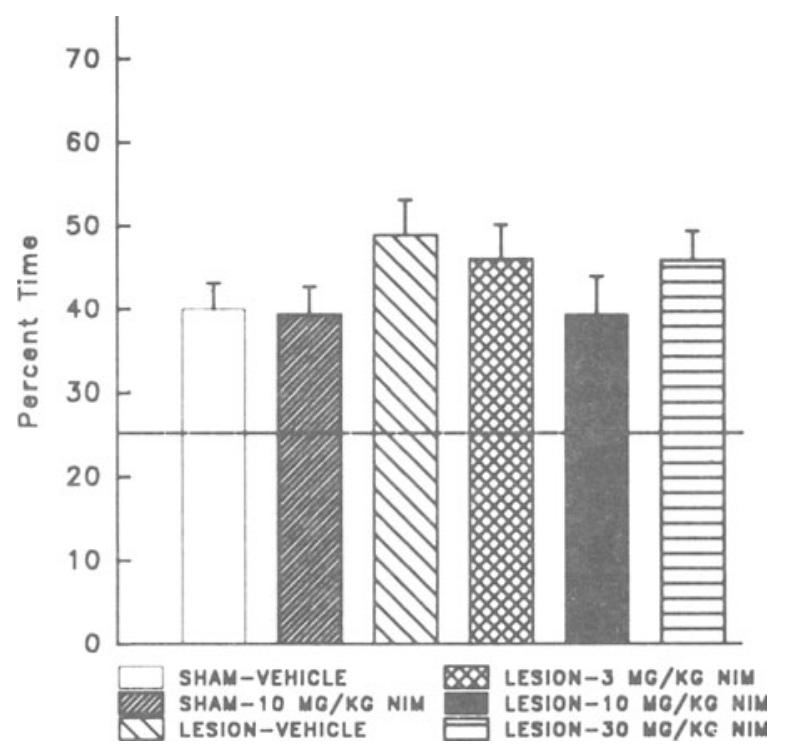

Figure 2. Percent time $(M \pm S E M ; n=7-10)$ spent in gool quadrant during Probe 1. This probe trial was conducted immediately after completion of acquibition training. Nimodipine or vehicle treatments had not started at this point. For all animals, the percentage of time spent in the goal quadrant was significantly greater thnn chance level of $25 \%$ (NIM = nimodipine).

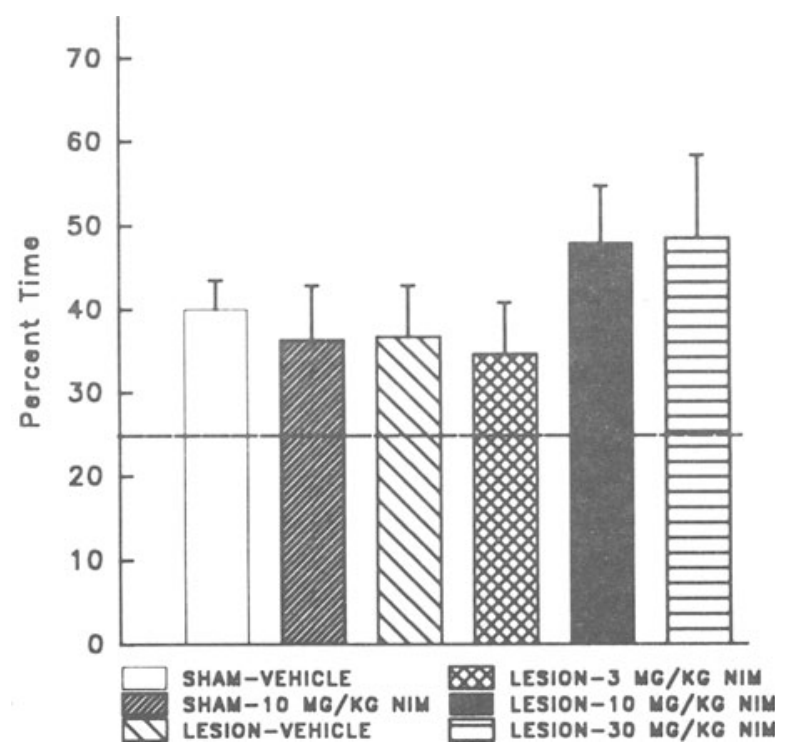

Figure 3. Percent time $(M \pm S E M ; n=7-10)$ spent in gool quadrant during Probe 2 . This probe trial (30 sec) was conducted 7 days postsurgery (sham or lesion) and after the start of nimodipine or vehicle treatment. No significant lesion or drug effect was observed at this point (NIM = nimodipine).

used in all previous testing. All the groups performed at levels above chance (all $p s<.001$ ), except the rats in the lesion-vehicle group. This finding was interpreted as a lesion-induced deficit in water maze performance in lesion-vehicle rats. Nimodipine appeared to protect against this effect, as shown in the data from the nimodipinetreated rats. 


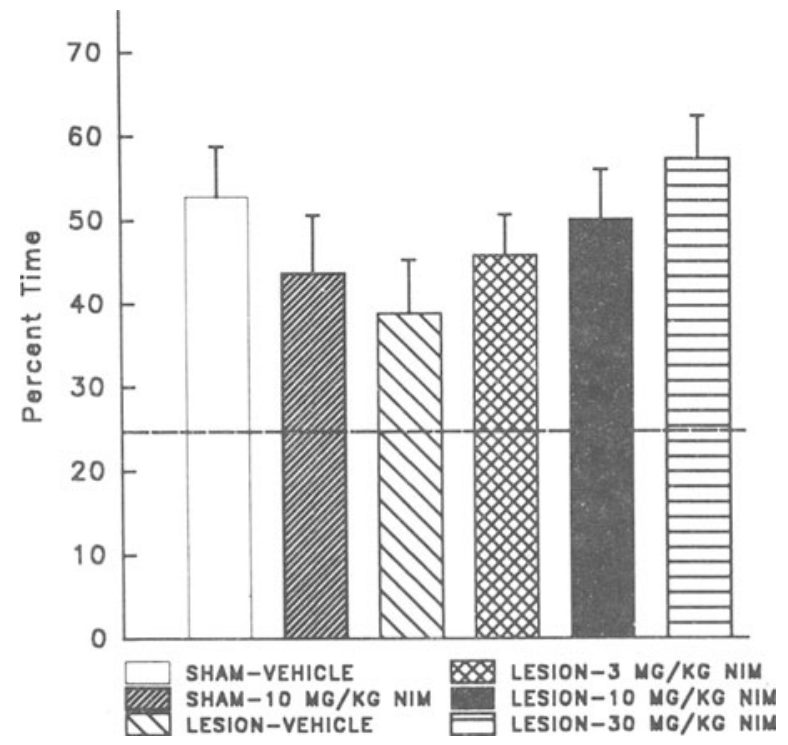

Figure 4. Percent time $(M \pm S E M ; n=7-10)$ spent in goal quadrant during Probe 3 . This probe trial $(30 \mathrm{sec}$ ) was conducted 1 day after four additional training trials to the same escape platform location utilized during initial training. The lesion-vehicle group did not perform at a level above chance, but this effect was not seen in control rats nor in rats given MS lesions and treated with nimodipine (NIM = nimodipine).

Comparisons of Probes 1, 2, and 3. Comparisons of Probe 1 (presurgery) performance with Probe 2 and Probe 3 are shown in Figures 5A and 5B, respectively. During Probe 2 , which was conducted 7 days postsurgery, all the groups had a decrease in the amount of time spent in the goal quadrant, compared with Probe 1 (presurgery), except the rats in the lesion-10-mg/kg and lesion-30$\mathrm{mg} / \mathrm{kg}$ nimodipine groups. A comparison of Probes 3 and 1 indicated that all of the groups, except the lesion-vehicle group, performed at a level higher than that observed during Probe 1. Statistical significance was achieved only in the lesion-30-mg/kg nimodipine group $(p<.05)$.

\section{DISCUSSION}

Prior to either surgery or drug treatment, rats were trained to learn the location of an escape platform. In Probe 1 , which was conducted immediately after initial training was completed, all of the rats were spending a significantly higher percentage of time in their respective goal quadrants (i.e., location of escape platform) compared with chance performance. This finding indicated that the rats had learned the general location of the escape platform. Probe 2 was conducted 7 days postsurgery and after the start of drug or vehicle treatments. At this point, no discernable drug or lesion effect was found. In fact, in all the groups, except the lesion-10-mg/kg nimodipine and lesion $-30-\mathrm{mg} / \mathrm{kg}$ nimodipine groups, decreases (nonsignificant) in the time spent in the goal quadrant, compared with presurgery performance, were found. This effect was possibly due to the passage of time, because a small decrease was found in the sham-vehicle (control) animals. Hagan et al. (1988) reported a decline in water maze performance (forgetting) in control rats and rats with medial septal lesions over a period of days. Also, there is evidence to suggest that medial septal nucleus (MS) lesions may not affect water maze performance (Barone, Nanry, Mundy, McGinty, \& Tilson, 1991; Decker, Radek, Majchrzak, \& Anderson, 1992), but it is difficult to compare this across studies because of differences in methods (e.g., rat strains; behavioral paradigms).

After Probe 2, the rats were given four additional training trials (one per day) with the same goal quadrant that was utilized during the initial acquisition. Although there were no significant group differences over the course of additional training, Probe 3 revealed an apparent lesion effect. The amount of time spent in the goal quadrant by the lesion-vehicle animals declined (compared with pre-
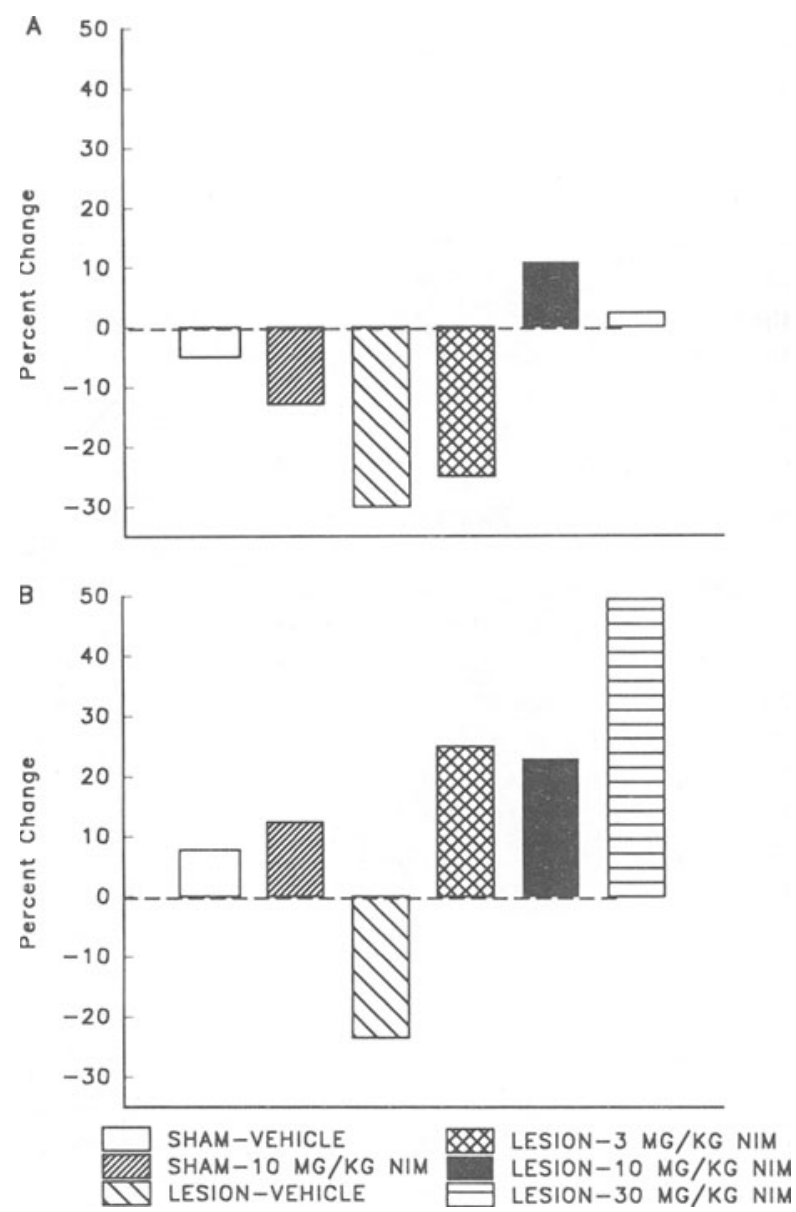

Figure 5. Percent change in time (median; $n=7-10$ ) spent in the goal quadrant between Probes 1 and 2 (A), and between Probes 1 and 3 (B). During Probe 2 (A), only the lesion $-10-\mathrm{mg} / \mathrm{kg}$ nimodipine and lesion $-30-\mathrm{mg} / \mathrm{kg}$ nimodipine groups did not show a decrease in percentage of time spent in the goal quadrant relative to Probe 1 (presurgery). During Probe 3, all groups showed an increase in the percentage of time spent in the goal quadrant relative to Probe 1 , except the lesion-vehicle group. As in control animals, this effect was not found in the rats treated with nimodipine (NIM = nimodipine). 
lesion performance) to a level that was not statistically greater than chance. In all other groups, the performance level was significantly above chance. An examination of Figure 5B, comparing Probe 1 (prelesion) with Probe 3, indicates that there was a relative increase in the percentage of time spent in the goal quadrant for each group, except in the lesion-vehicle group. Clearly, there was not a robust lesion-induced deficit, perhaps due to the limited extent of neuronal damage. However, the results of this investigation indicated that the rats with small MS lesions were unable to enhance their ability to remember a spatial location that was learned prior to surgery when additional training was given. In addition, the lesioned animals treated with nimodipine were able to improve their performance with additional training.

Nimodipine has beneficial effects on cognitive performance in rats with hippocampal lesions (Finger, Green, Tarnoff, Mortman, \& Anderson, 1990; Nelson, Bawa, \& Finger, 1992) and in aged nonhuman primates (Sandin, Jasmin, \& LeVere, 1990). In the present investigation, nimodipine treatment was found to have a beneficial effect on water maze performance in rats with medial septal lesions. One factor connecting these studies could be disruption of cholinergic neurotransmission in the hippocampus. There is research that suggests nimodipine administration may influence cholinergic activity in the hippocampus (Levy et al., 1991), but nimodipine has additional pharmacological actions in the CNS that may influence other neurotransmitter systems affected in models of cognitive dysfunction (Scriabine et al., 1989). On the basis of evidence suggesting $\mathrm{Ca}^{2+}$-activated cytotoxic mechanisms, Branconnier, Branconnier, Walshe, McCarthy, and Morse (1992) proposed a role for chronic nimodipine administration-the possible treatment and prevention of neurodegenerative changes associated with aging. In a hippocampal lesion model, Nelson et al . (1992) suggested nimodipine's neuroprotective action is due to vasodilatory effects and/or by maintenance of calcium homeostasis. In humans, nimodipine has been found to be effective for certain types of memory loss associated with Alzheimer's disease (Branconnier, Harto, \& Walsh, in press; Tollefson, 1990), and it is currently approved for the treatment of age-associated dementia in several countries (Grobe-Einsler, in press).

In conclusion, the results of this study suggest that MS lesions can induce a retention deficit in the Morris water maze, and that this deficit can be prevented by treatment with nimodipine. This research supports accumulating evidence that nimodipine may serve as a useful therapeutic agent in conditions with associated cognitive decline.

\section{REFERENCES}

Barone, S., Jr., Nanry, K. P., Mundy, W. R., McGinty, J. F., \& TiLson, H. A. (1991). Spatial learning deficits are not solely due to cholinergic deficits following medial septal lesions with colchicine. Psychobiology, 19, 41-50.
Branconnier, R. J., Branconnier, M. E., Walshe, T. M., McCarTHY, C., \& MORSE, P.-A. (1992). Blocking the $\mathrm{Ca}^{2+}$-activated cytotoxic mechanisms of cholinergic neuronal death: $A$ novel treatment strategy for Alzheimer's disease. Psychopharmacology Bulletin. 28. 175-181

Branconnier, R. J., Harto, N. E. \& Walshe, T. M. (in press). Nimodipine slows the progressive memory impairment of Alzheimer's disease. Progress in Neuropsychopharmacology \& Biological Psychiatry.

Cassel, J. C., Neufang, B., Kelche, C., Aiple, F., Will, B. E., HertTING, G., JACKisch, R. (1992). Effects of septal and/or raphe cell suspension grafts on hippocampal choline acetyltransferase activity, high affinity synaptosomal uptake of choline and serotonin, and behavior in rats with extensive septohippocampal lesions. Brain Research, 585, 243-254.

DeCKer, M. W., RADEK, R. J., Majchrzak, M. J., a ANDerson, D. J. (1992). Differential effects of medial septal lesions on spatial-memory tasks. Psychobiology, 20, 9-17.

Deyo, R. A., Straube, K. T., \&isterhoft, J. F. (1989). Nimodipine facilitates trace conditioning of the eye-blink response in aging rabbits. Science, 243, 809-811.

Finger, S., Green, L., Tarnoff, M., Mortman, K. D., \& AnderSON, A. B. (1990). Nimodipine enhances new learning after hippocampal damage. Experimental Neurology, 109, 279-285.

Fischer, W., GAGe, F. H., Bü̈KLund, A. (1989). Degenerative changes in forebrain cholinergic nuclei correlate with cognitive impairments in aged rats. European Journal of Neuroscience. 1. 34-45.

Fischer, W., Wictorin, K., BuörkLUNd, A., Williams, L. R., VARON, S., GAGE, F. H. (1987). Amelioration of cholinergic neuron atrophy and spatial memory impairment in aged rats by nerve growth factor. Nature, 329, 65-68.

Grobe-EinsLer, R. (in press). Clinical results with nimodipine and related disorders. In A. Scriabine, R. A. Janis, \& D. J. Triggle (Eds.), Drugs in development (Vol. 2). Branford, CT: Neva Press.

hagan, J. J., Salamone, J. D., Simpson, J., Iversen, S. D., Morris, R. G. M. (1988). Place navigation in rats is impaired by lesions of medial septum and diagonal band but not nucleus basalis magnocellularis. Behavioural Brain Research, 27, 9-20.

Hepler, D. J., Olton, D. S., Wenk, G. L., Coyle, J. T. (1985). Lesions in nucleus basalis magnocellularis and medial septal area of rats produce qualitatively similar memory impairments. Journal of Neuroscience, 5, 866-873.

Kinoshita, H., Kameyama, T., Hasegawa, T., Nabeshima, T. (1992). Effects of vinconate on spatial learning impairments induced by medial septal lesion in rats. Life Sciences, 51, 267-273.

Krol, G. J., Lettieri, J. T., Mazzu, A. L., Burkholder, D. E., Birkett, J. P., TAYloR, R. J., BON, C. (1987). Bioequivalence of different nitrendipine tablet dosage formulations. Journal of Cardiovascular Pharmacology, 9(Suppl. 4), s129-s135.

LeVere, T. E., Brugler, T., Sandin, M., Gray-Silva, S. (1989). Recovery of function after brain damage: Facilitation by the calcium entry blocker nimodipine. Behavioural Neuroscience, 103, 561-565. Levy, A., Kong, R. M., Stillman, M. J., Shukitt-Hale, B., KaDar, T., Rauch, T. M., Lieberman, H. R. (1991). Nimodipine improves spatial working memory and elevates hippocampal acetylcholine in young rats. Pharmacology, Biochemistry \& Behavior, 39, 781-786.

LewIS, P. R., Shute, C. C. D. (1967). The cholinergic limbic system: Projections to hippocampal formation, medial cortex, nuclei of the ascending cholinergic reticular system, and the subfornical organ and supra-optic crest. Brain, 90, 521-540.

Matsuoka, N., Maeda, N., Ohxubo, Y., Yamaguchi, 1. (1991). Differential effects of physostigmine and pilocarpine on the spatial memory deficits produced by two septo-hippocampal deafferentations in rats. Brain Research, 559, 233-240.

McMonagle-Strucko, K., \&anelli, R. J. (1993). Enhanced acquisition of reversal training in a spatial leaming task in rats treated with chronic nimodipine. Pharmacology, Biochemistry \& Behavior, 44, 827-835. 
Mesulam, M.-M., Mufson, E. J., Wainer, B. H., \& Levey, A. I. (1983). Central cholinergic pathways in the rat: An overview based on an alternative nomenclature (Ch1-Ch6). Neuroscience, 10, 1185-1201.

Nelson, C., Bawa, J., \& Finger, S. (1992). Radial maze performance after hippocampal lesions: Beneficial effects of nimodipine. Restorative Neurology \& Neuroscience, 4, 33-40.

Pallage, V., Orenstein, D., \& Will, B. (1992). Nerve growth factor and septal grafts: A study of behavioral recovery following partial damage to the septum in rats. Behavioural Brain Research, 47, $1-12$.

Paxinos, G., \& WATSON, C. (1986). The rat brain in stereotaxic coordinates. Sydney: Academic Press.

Pellegrino, L. J., Pellegrino, A. S., \& Cushman, A. J. (1979). A stereotaxic atlas of the rat brain. New York: Plenum.
Sandin, M., Jasmin, S., \& LeVere, T. E. (1990). Aging and cognition: Facilitation of recent memory in aged nonhuman primates by nimodipine. Neurobiology of Aging, 11, 567-571.

Scriabine, A., Schuurman, T., Traber, J. (1989). Pharmacological basis for the use of nimodipine in central nervous system disorders. FASEB Journal, 3, 1799-1806.

Tollefson, G. D. (1990). Short-term effects of calcium channel blocker nimodipine (Bay-e-9736) in the management of primary degenerative dementia. Biological Psychiatry, 27, 1133-1142.

(Manuscript received February 23, 1993; revision accepted for publication May 6, 1993.) 